ORIGINAL ARTICLE

\title{
Frequency of Hyponatremia and Hypokalemia in Children with Acute Diarrhea
}

\author{
MUHAMMAD ARIF ${ }^{1}$, ASIF SALEEM AFRIDI ${ }^{2}$, FARMAN ALI ${ }^{3}$, SYED UL ABRAR BANURI ${ }^{4}$, MUHAMMAD SALMAN ${ }^{5}$, \\ MARJEENA KHAN ${ }^{6}$ \\ ${ }^{1}$ Associate Professor, Pediatric Department, North West General Hospital, Peshawar \\ ${ }^{2,3}$ Senior Registrar, Pediatric Department, North West General Hospital, Peshawar \\ ${ }^{4}$ Resident Medical Officer, Pediatric Department, North West General Hospital, Peshawar \\ ${ }^{5}$ Senior Registrar, Pediatric Department, North West General Hospital, Peshawar \\ ${ }^{6}$ Medical Officer, North West General Hospital, Peshawar \\ Corresponding author: Dr. Farman Ali, Email: farman432000@yahoo.com, Cell No: +923345403130
}

\begin{abstract}
Objective: To determine the frequency of sodium and potassium abnormalities (hyponatremia and hypokalemia) in children presented with acute diarrhea.

Study Design: Prospective Study

Place and Duration: Study was conducted at Pediatric department of North West General Hospital, Peshawar during the period from July 2020 to June 2021 (for one Year).

Methodology: One hundred and thirty patients of both genders having age upto 5 years presented with acute diarrhea were enrolled in this study. Clinical examination was done after taking written informed consent from patients parents/guardians. Blood sample was taken and sent to laboratory to examine sodium and potassium levels. Data was analyzed by SPSS 24.0.

Results: There were $72(55.38 \%)$ males while 58 (44.62\%) patients were females with mean age $2.38 \pm 1.52$ years. Mean disease duration was $3.54 \pm 1.33$ days. Hyponatremia was found in $40(30.77 \%)$ patients and hypokalemia was observed in 52 (40\%) patients.

Conclusion: Sodium and potassium abnormalities are very common in children with acute diarrhea and can lead to high rate of morbidity and mortality. We concluded that frequency of hyponatremia and hypokalemia were very high in children with acute diarrhea.
\end{abstract}

Keywords: Acute Diarrhea, Hyponatremia, Hypokalemia, Children

\section{INTRODUCTION}

One of the most common reasons paediatric patients are admitted is acute gastroenteritis. In developing countries, it is a major cause of morbidity and mortality among children [1]. Regardless of the cause of the diarrhoea, fluid loss can lead to serious complications that necessitate hospitalisation or even prove fatal if proper measures are not taken quickly enough. Diarrhea and dehydration can be caused by a variety of pathogens, including bacteria and viruses [2].

Diarrhea is caused by two mechanisms: damage to the villous brush border and the release of toxin, which can cause an increase in intestinal fluid secretion beyond the digestive tract's capacity. Even though diarrhoea is still common, the number of children who visit their paediatrician because of diarrhoea and its complications has decreased significantly [3]. The use of oral rehydration solution has been linked to a decrease in diarrheal disease mortality. Because the sodium coupled solute co-transport mechanism remains intact even in severe diarrhoea, oral rehydration solution is effective in treating diarrheal diseases in children [4]. Increased frequency and altered stool consistency are the most common symptoms in children with simple diarrhoea. Vomiting and abdominal pain are common side effects. Dehydration-related complications like hypovolemic shock and renal failure can develop in these children if proper treatment is not provided. This can cause neurological symptoms like lethargy, irritability, and convulsions in some children.

Dehydration, electrolyte imbalance, and other consequences of untreated diarrhoea can be disastrous in children under the age of 5, especially [6]. Children with diarrhoea are more likely to have electrolyte imbalances, such as hypokalemia, hyponatremia, and altered urea and creatinine. In these kids, it's unusual to see hyperkalemia or hypernatremia. It's important to treat electrolyte imbalances when they occur in patients with diarrhoea by replacing sodium or potassium deficiency with normal levels. Patients who receive only intravenous fluids while in the hospital are more likely to develop hypernatremia dehydration [7]. Newborn and infants are also susceptible, and symptoms such as irritability, loud crying, and weakness are common. It can present as altered sensorium, diuresis, and fever in older children. Dehydration that results in hypernatraemia necessitates replenishing the body's water reserves. This water deficit in the body must be made up by drinking enough fluid to make up for the loss. The amount of fluid needed depends on the total water deficit in the body and the sodium concentration in the fluid being consumed.

An electrolyte imbalance can be treated with oral rehydration solution, intravenous fluids, and electrolyte balance correction. Patients who arrive at the hospital dehydrated may require admission to a paediatric intensive care unit where they will receive appropriate intensive care as well as shock management. Rehydration and electrolyte balance correction may be necessary in cases where bacterial aetiology is confirmed, in addition to appropriate antibiotics [9].

We conducted present study with aimed to determine the frequency of sodium and potassium abnormalities in 
children having ages upto 5 years and presented with acute diarrhea.

\section{MATERIALS AND METHODS}

This prospective/cohort study was conducted at Pediatric department of North West General Hospital, Peshawar during the period from July 2020 to June 2021 (for one Year). Total 130 patients of both genders having age up to 5 years presented with acute diarrhea were enrolled in this study. Clinical examination was done after taking written informed consent from patients parents/guardians. All patients were asked about their age, gender, height, and weight. The parents' or guardians' socioeconomic standing was also taken into consideration. It was also noted if the patient had any co-existing illnesses. To get an accurate picture of the patient's health history, we looked at things like stool frequency, vomiting, pain in the abdominal area, and how much the baby cried. We also looked at things like lethargy and refusal to feed in infants. Those who were excluded included children under the age of one month (Neonates), seriously ill patients, children with serious comorbid conditions that could have an impact on the outcome, and children who had diarrhoea for more than two weeks (persistent diarrhoea).

Before being admitted to the hospital, caregivers were questioned about the history of giving the child ORS, and if it had been, the procedure for making ORS was specifically requested to determine whether or not preparing ORS was appropriate. A variety of ORS preparations were used depending on the history provided by parents or caregivers, such as concentrate or dilute. Dehydration signs and severity were discovered after a thorough clinical examination. A stool test was performed.

In all patients $2 \mathrm{ml}$ venous blood was collected and serum sodium and serum potassium levels were determined. Hypokalemia was defined as potassium level $<3.5 \mathrm{mmol} / \mathrm{l}$ and sodium level $<130 \mathrm{mmol} / \mathrm{l}$ was defines as hyponatremia. All the data was analyzed by SPSS 24.0.

\section{RESULTS}

Out of 130 patients, 72 (55.38\%) were males while 58 $(44.62 \%)$ patients were females. Mean age was $2.38 \pm 1.52$ years. Mean disease duration was $3.54 \pm 1.33$ days. 70 $(53.85 \%)$ patients had urban residence while 60 (46.15\%) had rural residency. $40(30.77 \%)$ patients had low socio0economic status, 60 (46.15\%) had middle and 30 $(23.08 \%)$ had high socio-economic status. (Table 1)

Table No 1: Baseline details of all the patients

\begin{tabular}{|l|l|l|}
\hline Characteristics & Frequency No. & \%age \\
\hline Mean age & $2.38 \pm 1.52$ & - \\
\hline Disease Duration (days) & $3.54 \pm 1.33$ & - \\
\hline Gender & 72 & 55.38 \\
\hline Male & 58 & 44.62 \\
\hline Female & 70 & 53.85 \\
\hline Residence & 46.15 \\
\hline Urban & 60 & 30.77 \\
\hline Rural & 40 & 46.15 \\
\hline Socio-economic Status & 60 & 23.08 \\
\hline Low & 30 & \\
\hline Middle &
\end{tabular}

According to the clinical presentation, all patients had loose motion 130 (100\%), 90 (69.23\%) patients had abdominal pain, $45(34.62 \%)$ had fever, 38 (29.23\%) patients had vomiting, and 35 (26.92\%) had lethargy. (Figure 1)

Figure No 1: Clinical presentation of all the patients

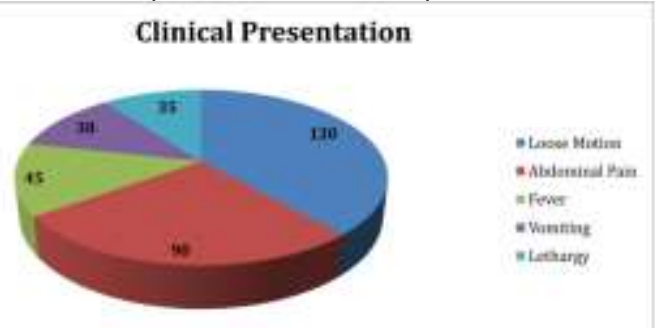

We found that $40(30.77 \%)$ patients had serum sodium level <3.5 mmol/l (hyponatremia) while 90 (69.23\%) patients had serum sodium level in normal range. (Figure 2)

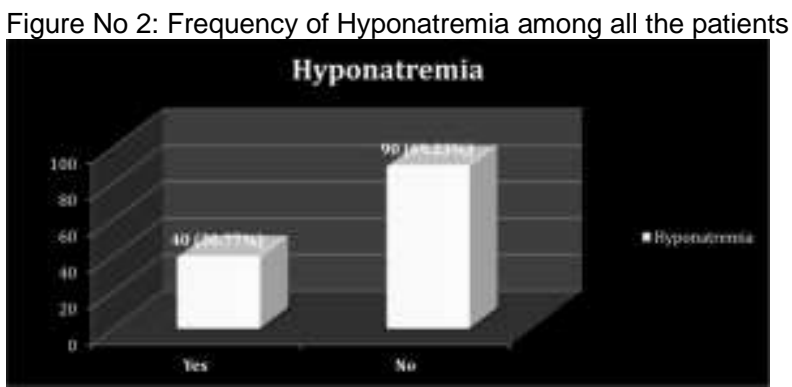

Hypokalemia was observed in 52 (40\%) patients with potassium level $<130 \mathrm{mmol} / \mathrm{l}$ while $78(60 \%)$ patients had potassium level $>130 \mathrm{mmol} / \mathrm{l}$. (Figure 3)

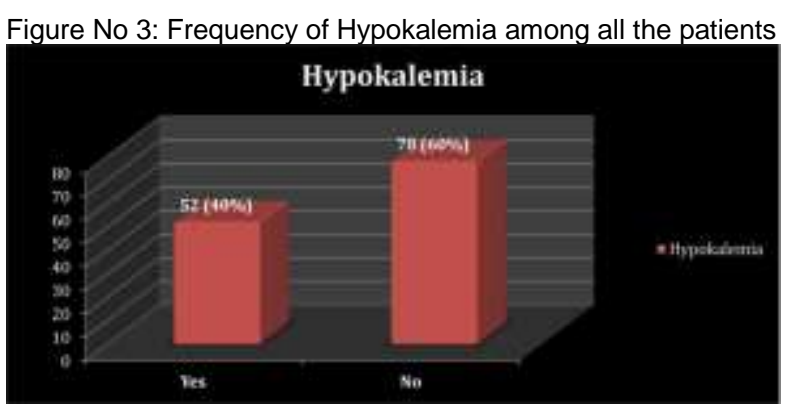

\section{DISCUSSION}

Worldwide, diarrhea is one of the most common life threatening disorders among children having ages up to 5 years. Acute diarrhea can lead to severe morbidity and even mortality if early and proper management didn't provided. Many of complication associated with diarrhea, in which sodium and potassium abnormalities are commonly found and these complications may lead to higher rate of morbidity and mortality [10-11].

In developing countries, diarrheal diseases are a major cause of morbidity and mortality. If they aren't breastfed, infants are more likely to get gastroenteritis than if they are. Unhygienic feeding practices and malnutrition are also risk factors for gastroenteritis development. When it comes to gastroenteritis, young children are especially 
vulnerable because of their large body surfaces, which cause them to lose water at a faster rate. Because of the higher water content, these children are more likely to develop an electrolyte imbalance [12]. We conducted this study with aimed to determine the sodium and potassium abnormalities such as hyponatremia and hypokalemia in children with acute diarrhea. In this regard 130 patients of either gender were examined. Majority 72 (55.38\%) were males while $58(44.62 \%)$ patients were females. Mean age was $2.38 \pm 1.52$ years and majority $65 \%$ were ages 1 to 3 years. These results were comparable to many of previous studies in which male patients were high in numbers $60 \%$ to $70 \%$ and the average age of patients was 2 years [1314]. Mean disease duration was $3.54 \pm 1.33$ days. 70 (53.85\%) patients had urban residence while $60(46.15 \%)$ had rural residency. $40(30.77 \%)$ patients had low socioeconomic status, 60 (46.15\%) had middle and 30 (23.08\%) had high socio-economic status.

In present study we found that all patients had loose motion 130 (100\%), 90 (69.23\%) patients had abdominal pain, $45(34.62 \%)$ had fever, $38(29.23 \%)$ patients had vomiting, and $35(26.92 \%)$ had lethargy. Previous studies demonstrated that after loose motion abdominal pain, fever, and vomiting were the frequently found clinical presentation $[12,15]$.

In our study, we found that $40(30.77 \%)$ patients had serum sodium level $<3.5 \mathrm{mmol} / \mathrm{l}$ (hyponatremia) while 90 $(69.23 \%)$ patients had serum sodium level in normal range. Hypokalemia was observed in 52 (40\%) patients with potassium level $<130 \mathrm{mmol} / \mathrm{l}$ while $78(60 \%)$ patients had potassium level $>130 \mathrm{mmol} / \mathrm{l}$. Sushil Kuamr Bakolia et al [16] reported that out of 100 malnourished children with diarrhea, $15 \%$ patients had hyponatremia while hypokalemia was observed in $10 \%$ cases.

A study conducted in Bangladesh by Abu tayyab et al [17] reported that $32.8 \%$ children had serum sodium level $<3.5 \mathrm{mmol} / \mathrm{l}$ and $43.2 \%$ patients had serum potassium level $<130 \mathrm{mmol} / \mathrm{l}$.

An investigation carried out in Pakistan's Quetta found that out of 174 people suffering from acute diarrhoea, $43.7 \%$ had hypokalemia and only $5.7 \%$ had hyponatremia [18]. There were $41.6 \%$ of study participants with a sodium disorder (severe hyponatraemia with serum $\mathrm{Na} 120 \mathrm{meq} / \mathrm{L}$, $23.6 \%$ with serum $\mathrm{Na} 120 \mathrm{meq} / \mathrm{L}$ at $135 \mathrm{meq} / \mathrm{L}$, and $14 \%$ of hypernatremia with serum $\mathrm{Na}>145 \mathrm{meq} / \mathrm{L}$ ) according to an Iranian study. Hypokalaemia (serum K3.5 mmol/L) was found in $17.2 \%$ of the participants, while hyperkalaemia (serum $\mathrm{K}>5.5 \mathrm{mmol} / \mathrm{L}$ ) was found in $3.7 \%$ of the participants.

Next to isonatremic dehydration, hyponatremic dehydration occurs more frequently in children who have taken diluted ORS. The history and clinical signs and symptoms may point to hyponatremic dehydration. More people being aware of ORS preparation could help reduce the incidence of AGE-related hyponatremia [19].

\section{CONCLUSION}

Sodium and potassium abnormalities are very common in children with acute diarrhea and can lead to high rate of morbidity and mortality. We concluded that frequency of hyponatremia and hypokalemia were very high in children with acute diarrhea.

\section{REFERENCES}

1. Mathew S, Smatti MK, Al Ansari K, Nasrallah GK, Al Thani AA, Yassine HM. Mixed Viral-Bacterial Infections and Their Effects on Gut Microbiota and Clinical Illnesses in Children. Sci Rep. 2019 Jan 29;9(1):865.

2. Alumbo E, Branchi M, Malorgio C, Siani A, Bonora G. Diarrhea in children: etiology and clinical aspects. Minerva Pediatr. 2010 Aug;62(4):347-51.

3. Sánchez-Uribe E, Esparza-Aguilar M, Parashar UD, Richardson V. SustainedReduction of Childhood Diarrhea-Related Mortality and Hospitalizations in Mexico After Rotavirus Vaccine Universalization. Clin Infect Dis. 2016 May 1;62 Suppl2:S133-9.

4. World Health Organization WHO. Division of Diarrhoeal and Acute RespiratoryDisease Control. Rational management of diarrhoea in children. Essent DrugsMonit. 1991;(11):10-1.

5. Nathanson S, Kwon T, Elmaleh M, et al. Acute neurological involvement in diarrhea-associated hemolytic uremic syndrome. Clin J Am Soc Nephrol. 2010;5(7):1218-1228.

6. Lakshminarayanan S, Jayalakshmy $R$. Diarrheal diseases among children in India: Current scenario and future perspectives. J Nat Sci Biol Med. 2015;6(1):24-28.

7. Wu CJ, Li CS. The impact of iatrogenic hypernatremia on the prognosis ofcritical patients. Zhongguo Wei Zhong Bing Ji Jiu Yi Xue. 2009 Aug;21(8):474-7.

8. Kim SW. Hypernatemia : successful treatment. Electrolyte Blood Press. 2006;4(2):66-71. Koletzko S, Osterrieder S. Acute infectious diarrhea in children. Dtsch Arztebl Int. 2009;106(33):539-548.

9. Meyers RS. Pediatric fluid and electrolyte therapy. J Pediatr Pharmacol Ther. 2009; 14(4):204-211.

10. Pratima P, Padma Geethanjali M. Study of electrolyte imbalance in children suffering from acute gastroenteritis of under 5 age group. J. Evid. Based Med. Healthc. 2018; 5(46), 3210-3213.

11. Sreedharan R. Major Symptoms and Signs of Digestive Tract Disorders. In: Kaliegman RM, Stanton BF, Geme JW, Schor NF, Behrman RE. Editors. Nelson textbook paediatrics, 19th ed. Philadelphia: WB Saunders Company; 2011: 1243-45.

12. Mubarak A, Attaullah M, Abid H. Acute hypokalemic flaccid paralysis in malnourished children. Pak Pead J 2003;27(4):166.

13. Shah RH, Javdekar BB. Management of children with severe acute malnutrition: experience of nutrition rehabilitation centre at Baroda, Gujarat. Int J Contemp Pediatr. 2014 May;1(1):3-6.

14. Dhyani A, Ameta P, Patel JB, Goyal S. Clinical profile of children with diarrhoea admitted in pediatric intensive care unit of Bal Chikitsalay, M.B. Hospital, RNT Medical College, Udaipur, Rajasthan, India. Int J ContempPediatr2016; 3:1371- 4.

15. Bilal A, Sadiq MA, Haider N. Frequency of hyponatraemia and hypokalaemia in malnourished children with acute diarrhoea. $\mathrm{J}$ Pak Med Assoc. 2016 Sep;66(9):1077-1080. PMID: 27654723.

16. Sushil Kumar Bakolia, Gajendra Kumar Verma, Dinesh Kumar Barolia. The Frequency of Hyponatremia and Hypokalemia in Malnourished Children with Acute Diarrhea. IJMBS 2021. Volume 5, Issue 9; September: 2021; Page No.157-159.

17. Abu Tayab, Ariful Hoq. Acid-base and Electrolyte Disturbances in Children Presenting with Acute Watery Diarrhoea in Emergency Observation and Referral Unit of Dhaka Shishu (Children) Hospital. DS (Child) H J 2020; 36(2): 120-124.

18. Habibullah Babar, Sanaullah, Muhammad Rahim. Serum Electrolyte Disturbances in Acute Diarrhoea among Children Less Than 5 Years of Age. P J M H S Vol. 10, NO. 4, OCT DEC 2016.

19. Dastidar RG, Konar N (2017) A Study of Electrolyte Disturbances in a Child Presenting with Acute Gastroenteritis, with Special Emphasis on Hyponatremic Dehydration-A Hospital based Cross-Sectional Study. Pediatr Ther 7: 322. 